\title{
Continuous Limb Blood Flow Estimation in the Newborn Using Electrical Impedance Plethysmography
}

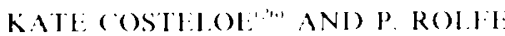 \\ Deparment of Paediatrics. John Radeliffe Hospital. Headingten. Oxford. Ingland
}

\begin{abstract}
Summary
This study aims to define a method for acquiring limb blood now data from newborn babies on a continuous basis which would be suitable for automatic processing. Pulsatile electrical impedance and strain gauge signals were analyzed in 3 different ways. The results were compared with estimates of flow derived from venous occlusion plethysmography with a mercury-in-rubber strain gauge. Measurements were made from 33 babies. The impedance technique was easier to perform than the strain gauge technique. The reproducibility of the various estimates of flow is shown in Table 3. The beat-to-beat reproducibility of simultaneous pulsatile measurements and of repeated measurements on different subjects was greater from the impedance recordings than from the strain gauge recordings. The results of linear regression analyses between the different flow estimates are shown in Table 4 . The best correlation with flow measured using venous occlusion plethysmography was with flow calculated from the impedance pulse height, $F\left(Z_{\text {max }}\right)(r=0.76 ; n=30 ; P<(0 .(0) 1)$. The regression line between these 2 variables was not statistically significantly different from the line of identity, $(P<0.98)$, and the intercept is close (o) zero.
\end{abstract}

The measurement of the impedance pulse height. $\Delta Z_{\max }$, and the subsequent calculation of $F\left(Z_{\text {max }}\right)$ could be automated and provide continuous beat-to-beat blood flow estimations.

\section{Speculation}

A method has been defined which is suitable for continuous estimation of limb blood flow in newborn babies under intensive care. It is believed that this simple technique will help the development of full understanding of the circulatory changes associated with events in the neonatal period and thus help to lead towards further improvements in the treatment of such infants.

It is likely that the changes in cardiac output and its distribution which may be associated with apnoeic atlacks and changes in blood gas iensions during the neonatal period are involved in the pathogenesis of permanent hrain damage To improve further the treatment of infants requiring intensive care, it is important that such circulatory changes are more fully understood. and to achieve this. there is a need for the development of simple. noninvasive metheds for the continuous extimation of blood flow

Venous occlusion plethysmography, using both air-filled (21. $23)$ and water-filled cuffs (5) or mercury in rubber strain gauges (9. 18. 19) has been used to estimate lower limb blood flow in the newhorn. However. this method does not allow continuous measurements to be made. and furthermore. the essentially mechanical techniques used are cumbersome and often difficult to apply. This is particularly the case when long-term studies are required on babies undergoing intensive care who require minimal handling and who are likely already to be encumbered by the attachment of physiologic monitoring apparatus. There is an additional ob- jection to venous occlusion plethysmography in that the repeated inflation and deflation of the occluding cuff may influence blood flow when multiple measurements are made rapidly

Electrical impedance plethysmography has been used in the adult to estimate limb blood flow and by comparison with mechanical techniques has been found to be simpler to use and unencumbering to the subject $(8)$. Estimates of limb blood flow have been derived both from venous occlusion plethysmography (12) and from the analysis of individual arterial pulses $(2,4,15$, 20). Such analyses include the straightforward measurement of pulse height (20) as well as more complex methods $(2,4,15)$ which aim to correct for inaccuracies introduced by venous and arterial runoff. In addition to providing quantitative estimates of limb blood flow, the impedance technique has been used for making qualitative assessments of peripheral arterial disease (1, 6. 14).

The use of pulse analysis clearly offers the possibility to derive estimates of blood flow on a beat by beat basis and. as such, has an obvious advantage compared with venous occlusion plethysmography. The aim of this study was 10 assess the feasibility and performance of electrical impedance plethysmography for the estimation of limb blood flow in ill newborn infants. L:stimation. of thow were made using various forms of pulse analysis and these were compared with estimates of flow derived from venous occlusion plethysmography using a mercury in rubber strain gauge. The ultimate goal of the study was to develop a method of analysis which would be suitable for automatic processing to derive blood how data on a continuous hasis.

\section{MATIRIALS INI) METHOIDS}

IIICTRIC A IMPLI)ANCI MIASIRIMINTS

A four-electrode system was used for impedance measurements. With this arrangement, a constant current is supplied to two outer current electrodes and the measurement of the voltage appearing between two inner voltage electrodes then provides an indication of electrical impedance. The instrument used in this study (P.M.S. l.td.. Slough. Berks. United Kingdom) produced a constant amplitude sinusoidal current of $2 \mathrm{~mA} \mathrm{rms}$ at $10(0 \mathrm{kH} /$ and had an output impedance of $13 \mathrm{kohm}$ at a load of 130 ohms.

The electrical impedance of hiologic tissue in which there is pulsatile blood flow consists of two components: a basal impedance. $Z_{\text {. }}$ ohm. with a superimposed pulsatile component. $\Delta 7$. ohm. which corresponds to pulsatile bloed flow within the tissue. $\Delta Z$ is


subtracted from the composite signal to allow adequate amplification of $\Delta Z$. The instrument used in this study had an automatic balancing circuit to achieve this. $Z_{1}$ was displayed in digital form on the instrument. and electrical outputs were available for recording $\Delta Z$ and its first derivative. $3 Z / \mathrm{dt} / \mathrm{ohms}$.

Measurements of the electrical impedance of infants legs were made using disposable hand electrodes. These consisted of selfadhesive tape having a strip of aluminum running along the center 
(3M electrode tape). One current electrode was placed around the foot. and the second was placed across the lower abdomen. The voltage sensing electrodes were positioned around the calf (Fig. 1). The adhesive tape on the voltage electrodes was trimmed to leave a sufficiently wide area of the calf for attachment of a mercury-in-rubber strain gauge. All electrodes were applied using electrode paste (Hewlett-Packard Redux cream), and no measurements were made until the electrodes had been applied for at least $10 \mathrm{~min}$. The importance of electrode position was investigated in a preliminary series of experiments by making recordings of $\Delta Z$. The ratio of $\Delta Z_{\text {mas }} / Z_{11}$ was determined for different values of voltage sensing electrode spacing. L. (Fig. 1).



Strain gauge measurements (22) were made using gauges constructed from mercury-filled silicone rubber tubing. internal diameter $0.5 \mathrm{~mm}$. external diameter $1 \mathrm{~mm}$. (Dow-("orning. Lid.). electrical contact with the mercury column being made with copper pins. The gauge formed one arm of a Wheatstone bridge. which was operated at constant current. The $95 \%$; response time of the gauge and bridge logether was found to be $16.5 \mathrm{msec}$, and the system will faithfully reproduce signals up to a frequency of 23 $\dot{H} \%$.

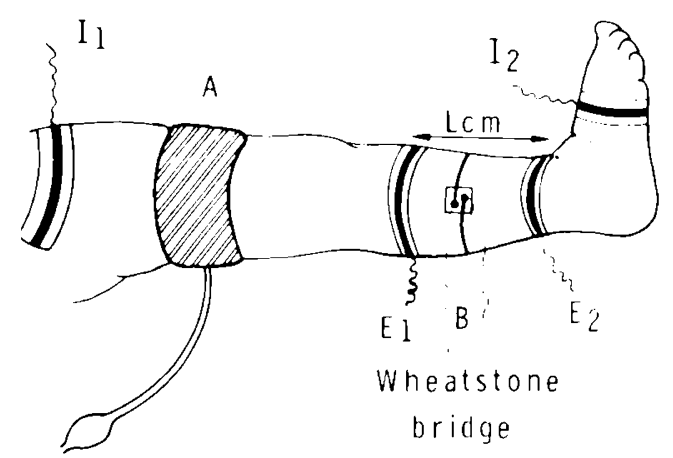

1 12. 1. Dhagram lo show postloms of mpedance electrodes and stran gauge on infants leg. $t$ sphygmomanometer cult: $B$. strain gauge: $l_{1} l_{2}$. impedance current electrodes: $E_{2} l:$ impedance recording electrodes: $l$. distance between impedance recording electrodes.
The gauge was passed once around the circumference of the calf, between the voltage sensing electrodes (Fig. 1), and was secured by a small Perspex mount. The tension in the gauge was maintained between 14 and $16 \mathrm{~g}$. The response of the gauge and bridge was found to be linear at the tensions used. Electrical calibration of the gauge was performed in situ by switching either $1 / 200$ th or $1 / 1000$ th increase in resistance into the Wheatstone bridge (7).

\section{RICORI)INGS}

A four-channel Hewlett-Packard direct writing recorder. type $74(14 \mathrm{~A}$. was used to collect permanent records of electrical impedance and strain gauge signals. Pulsatile recordings were made at a paper speed of $10 \mathrm{~cm} / \mathrm{sec}$ and venous occlusion recordings at a speed of 0.5 or $1 \mathrm{~cm} / \mathrm{sec}$.

Simultaneous recordings were made of strain gauge pulses, $\Delta Z$. and $\mathrm{d} Z / \mathrm{dt}$ (Fig. 2).

Venous acclion plethysmography was carried out by inflating a thigh encircling pressure cuff to $30 \mathrm{~mm} \mathrm{Hg}$. Between 5 and 8 occlusion slopes were obtained from such subject, approximately 30 sec being allowed between each occlusion.

\section{ANALYSIS OI RE(ORIINC;S}

\section{H.ICTRIC ML IMPEIOANCE PIISL ANAIYSIS}

The electrical impedance pulses were analysed in three different ways. The first two were attempts to yuantitate limb blood flow and were based upon the formula developed simultaneously by Nyboer (15. 16) and by Bonjer (3) which is commonly used for impedance flow calculations.

$$
\mathrm{V}=\rho \cdot\left(\mathrm{L} / \mathrm{Z}_{11}\right)^{2} \cdot \mathrm{Z}
$$

where $V$ is the pulse volume, $\mathrm{ml} \rho$ o is the electrical resistivity of blood $(0 \mathrm{hm} \mathrm{cm})$. $\mathrm{L}$ is the voltage electrode spacing $(\mathrm{cm}) . Z_{11}$ is the mean basal impedance (ohms) and $\Delta Z$ is the pulsatile impedance change (ohm).

The resistivity may be written as:

$$
\rho=Z_{11} \mathrm{~A} / \mathrm{L}
$$

where $A$ is the cross-sectional area of the limb segment. Substituting for $p$ in cyuation I yiclds.

$$
\Delta \mathrm{V}=(\mathrm{L} / \mathrm{Z}(\mathrm{Z}) \cdot \mathrm{A} \cdot \Delta \mathrm{Z}
$$

Thus $J \mathrm{~V}$ per $100 \mathrm{ml}$ of tissue $\left.=\left(\Delta \mathrm{Z} / \mathrm{Z}_{1}\right) \cdot 10\right)$.

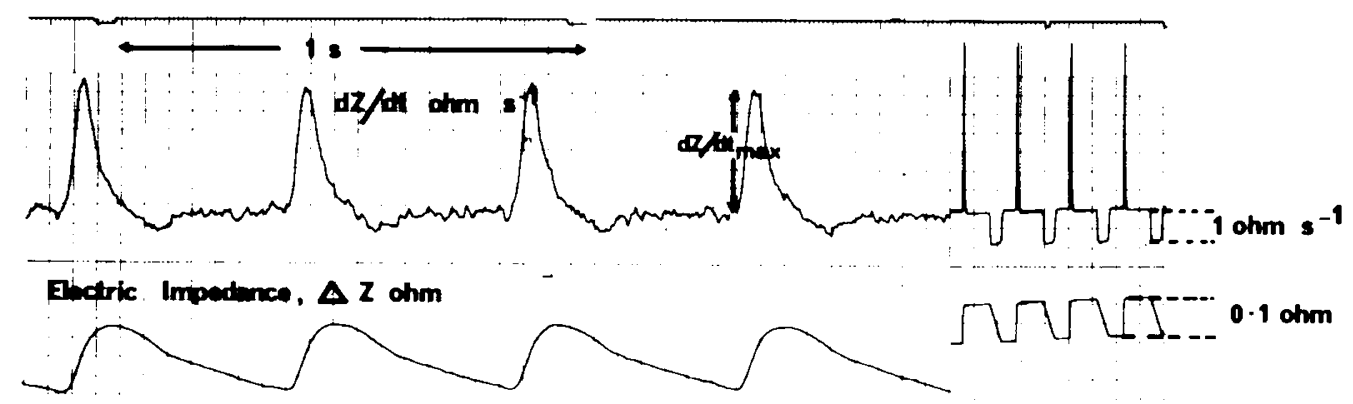

Strin Gave, $\Delta R$

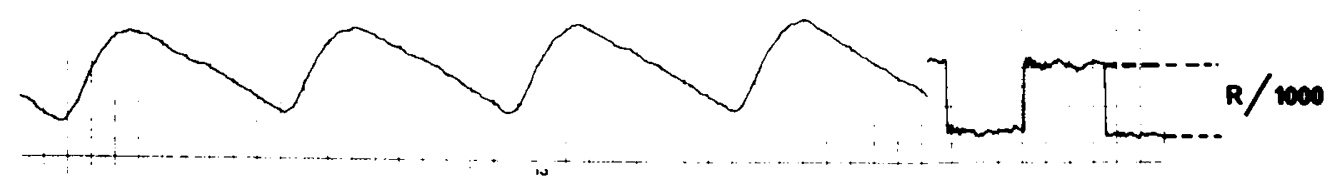

1.ig. 2. Trace of arterial pulsations from the calt of at newhorn haby recorded simultaneously using electrical inpedance. $\Delta Z$ and dZ dt, and mercuryin-rubber strain gatuge. The measurement of the maximum rate of impedance change $\mathrm{d} \%$. de.... is shown. 
The first method used for calculating flow simply uses the maximum pulsatile impedance height, $\Delta Z_{\text {tmax }}$ (Fig. 3 ), for the value of $\Delta \mathrm{Z}$ in equation 2 :

$$
F\left(Z_{\text {max }}\right)=\left(\Delta Z_{\text {max }} / Z_{11}\right) \cdot \dot{H} .100 \mathrm{ml}^{\prime} 100 \mathrm{ml}^{\prime} \cdot \min { }^{\prime}
$$

where $\dot{H}$ is the heart rate in beats per min.

The second method for calculating flow uses Nyboer and Bonjer's formula but uses the end-diastolic impedance slope, $\Delta Z_{1}$, (Fig. 3), as suggested by Brown et al. (4). The calculation is based on the assumption that there is no arterial tlow at the end of the cardiac cycle, and that calf venous flow is nonpulsatile. Thus, the change of impedance at the end of the cardiac cycle relates to mean venous flow alone. Because over the complete cardiac cycle inflow and outflow are equal. this slope averaged over the cycle will give mean arterial tlow:

$$
\mathrm{F}\left(Z_{1}\right)=\left(\Delta Z_{1}, / Z_{0}\right) \cdot 600() \mathrm{ml}^{1} 100 \mathrm{ml}^{\prime} \cdot \min { }^{\prime}
$$

where $\Delta Z_{1}$, is the impedance slope at the end of the pulse cycle. in ohm/sec.

The third variable measured from the impedance signals was the maximum rate of impedance change occurring during the inflow phase of the pulse cycle. $\mathrm{d} 7$. $/ \mathrm{dt}_{11 \mathrm{a}}$ (lig. 2). This value was estimated because the corresponding slope from transthoracic impedance pulses has been shown to be closely correlated with stroke volume (11). This measurement was made from the records of the first differential of $\Delta Z$ and was expressed in terms of $Z_{11}$.

Ten successive beats were analyzed from each impedance recording. The mean values of $F\left(Z_{\text {max }}\right) . F(Z D)$ ) and $\frac{d Z / d t_{\text {max }}}{Z_{11}}$ were then used for comparison with strain gauge measurements.

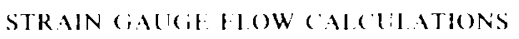

The pulsatile recordings from the strain gauge were analyzed in a similar fashion to the impedance recordings. (alculations were made using the equation derived from the work of Whitney (22):

$$
\Delta V=\Delta R / R \cdot 100
$$

where $\Delta V$ is the volume change per $100 \mathrm{ml}$ tissue. $\Delta R$ is the change in strain gauge resistance $(0 \mathrm{hm})$, and $R$ is the resting strain gauge resistance $(0 h \mathrm{~m})$. The use of electrical calibration as described above means that the actual value of $R$ need not be known.

The two estimations of llow from the strain gauge recordings were then made from the following:

$$
\mathrm{F}\left(\mathrm{SG}_{\operatorname{lnax}}\right)=\Delta \mathrm{S}\left(_{\max } / \mathrm{R} \cdot \dot{H} .100 \mathrm{ml} .100 \mathrm{ml}^{\prime} \cdot \min { }^{\prime}\right.
$$

where $\dot{H}=$ heart rate (beats/min)

and

$$
\mathrm{F}(\mathrm{S}(j \mathrm{D}))=\Delta \mathrm{S}(\mathrm{II}) / \mathrm{R} .0000 \mathrm{ml} .100 \mathrm{ml} \mathrm{m}^{\prime} \cdot \mathrm{min}{ }^{\prime}
$$

The terms $\Delta S\left(i_{1 \ldots+1}\right.$ and $\Delta S(i)$ relate to the maximum height of the strain gauge pulse and its end diastolic slope and are equivalent (o) $\Delta Z_{\mathrm{m} \text { ix }}$ and $\Delta Z_{1}$, in Figure 3 .

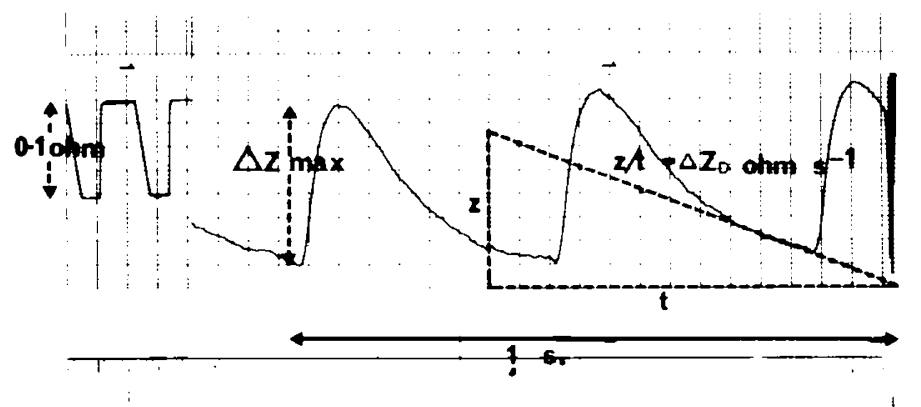

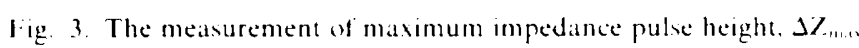
and slope at the end of the cardiac eycle. 37.0 ) from arterial impedance pulses.
The maximum change in strain gauge resistance seen during the inflow phase of the pulse cycle was expressed as $\frac{\mathrm{dR} / \mathrm{dt}_{\text {man }}}{\mathrm{R}}$.

The same ten successive beats from the strain gauge recording were analyzed as had been from the impedance recording.

Flow during venous occlusion was calculated from the strain gauge recording using the formula

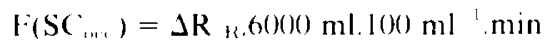

where $\Delta R$ is the change in strain gauge resistance per sec during venous occlusion

$$
\text { RIPROI)I (IBIIITY () HIOW ISIIMATIONS }
$$

The reproducibility of the three variables measured from the simultaneous pulsatile impedance and strain gauge recordings was investigated by calculating the coefficient of variation ( $\mathrm{C} V$ ):

$$
(\mathrm{V}=\text { (standard deviation/mean). } 100)^{\prime} ;
$$

The ( $V$ was calculated for each variable from the ten successive beats analy/ed. In addition. six babies had ten impedance recordings made at 30 -sec intervals. From these recordings, the ( $\mathrm{V}$ was calculated for heart rate, $Z_{\text {a }}$. mean $\mathrm{F}\left(Z_{\text {thax }}\right)$, the mean pulse volume calculated using $Z_{\text {m.i. }}$

The reproducibility of blood flow calculations made using the strain gauge during venous occlusion was estimated from data collected from a further six babies who each had 10 measurements made at 30 -sec intervals.

$$
\begin{gathered}
\text { (OMPARISON OI IMPLIDANCI ANI) STRAIN (INICII HIOW } \\
\text { ISTIMATIONS }
\end{gathered}
$$

To determine which of the three methods of impedance pulse analysis could best provide a reliable estimate of beat-to-beat limb blood flow. linear regression analysis was performed between each of the three estimates and flow calculated from strain gauge venous occlusion measurements. Linear regression analysis was also performed between the corresponding estimates of simultaneously recorded pulsatile impedance and strain gauge signals. In each case. when two flow estimates were heing compared. a test was performed to determine whether or not the regression line differed statistically significantly from the line of identity.

\section{SUBJEC"TS}

All the habies studied were patients on the Special care Baby Unit at the John Radeliffe Hospital. ('linical details of these babies are given in Table 1 . There was no selection in terms of maturity or size and babies both with and without clinical problems were studied. In no case was the infant's routine disturbed. and only brief handling was made as part of the measurement procedure. Informed parental consent was obtained before each study.

\section{RISLII.TS}

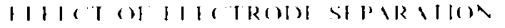

In live babies. impedance recordings were made with four or five different recording electrode positions on the leg. The ratio

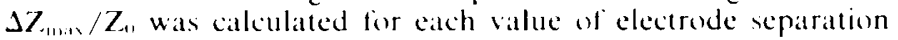
(L). (Fig. 1). The results are shown in Figure 4 and it can be seen that, with the exception of one baby (O) who was restless throughout the study, the ratio is constant.

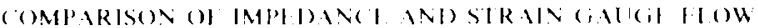 ISIIMIIIONS}

The results of the comparative impedance and strain gauge calculations collected in 33 babies are shown in Table 2 . As a general comment, the impedance lechnique was found to be easier to perform than the strain gauge technique. Pulsatile strain galuge 
Table 1. Clinical details of habie's

\begin{tabular}{|c|c|c|c|}
\hline Subject & Sex & $\left(j \mathrm{~A}^{\prime}\right.$ & B. Wt. (g) \\
\hline 1 & $\mathrm{~F}$ & 38 & 2060 \\
\hline 2 & $\mathrm{~F}$ & 36 & 1630 \\
\hline 3 & $\mathbf{M}$ & 34 & $2(x)$ \\
\hline 4 & $\mathbf{M}$ & 30 & $1304)$ \\
\hline 5 & $M$ & 37 & 3180 \\
\hline 6 & $M$ & 38 & 2930 \\
\hline 7 & $M$ & 34 & 2240 \\
\hline 8 & $\mathrm{~F}$ & 31 & 1130 \\
\hline 4 & $\mathrm{r}$ & 30 & 1180 \\
\hline 10 & $M$ & 35 & 2350 \\
\hline 11 & $M$ & 39 & 2280 \\
\hline 12 & $M$ & 35 & $220(4)$ \\
\hline 13 & $\mathrm{~F}$ & 34 & 1350 \\
\hline 14 & $M$ & 32 & 1350 \\
\hline 15 & $\mathbf{M}$ & 30 & 1355 \\
\hline 16 & $\mathbf{M}$ & 36 & $2 \times 35$ \\
\hline 17 & $M$ & 30 & $14(\%)$ \\
\hline 18 & $F$ & 35 & 1930 \\
\hline 19 & M & 30 & 1250 \\
\hline 20 & $\mathrm{~F}$ & 34 & 18001 \\
\hline 21 & $M$ & 30 & 16040 \\
\hline 22 & M & 27 & 1030 \\
\hline 23 & $M$ & 26 & 870 \\
\hline 24 & $\mathbf{M}$ & 34 & 2520 \\
\hline 25 & I & 32 & 1840 \\
\hline 26 & $\mathbf{M}$ & 33 & 1820 \\
\hline 27 & $M$ & 33 & $2(4)()$ \\
\hline 28 & $\mathrm{~F}$ & 33 & 1.560 \\
\hline 29 & $M$ & 35 & 2360 \\
\hline 30 & $\mathbf{M}$ & 30 & 1240 \\
\hline 31 & $\mathrm{~F}$ & 36 & 1920 \\
\hline 32 & $M$ & 32 & 12601 \\
\hline 33 & $\mathrm{r}$ & 30 & 1350 \\
\hline
\end{tabular}

\begin{tabular}{|c|c|}
\hline Jursing & Clinical comments \\
\hline$C_{\text {int }}$ & Microcephalic \\
\hline Cint & Well $^{2}$ \\
\hline (int & Well \\
\hline (in & Well \\
\hline IM] & TTN, pneumothorax, headbox oxygen \\
\hline IMI & $\begin{array}{l}\text { TIN. UAC in Rt. a.. leg blanched and catheter } \\
\text { withdrawn prior to study }\end{array}$ \\
\hline Inc & Well \\
\hline Inc & Twin. well \\
\hline$C_{\text {in }}$ & Twin. BPI following severe HMI) \\
\hline $\operatorname{Inc}$ & Mild HMD, headbox 0 : \\
\hline IMI & Severe B. A. irritable \\
\hline (iin & Well \\
\hline $\operatorname{Inc}$ & Well \\
\hline IMI & Severe HMD. IPPV \\
\hline IMI & Severe HM(). IVH, tits \\
\hline [M] & Severe HMD, bilat. pneumothorax. IPPV \\
\hline Inc & Well \\
\hline Inc & Well \\
\hline IMI & Severe HMD). heidhox (): \\
\hline Inc & Well \\
\hline Inc & Mild HMD. headhox 0 : \\
\hline IMI & $\begin{array}{l}\text { B. A. Severe HMD, thrombosis L. leg. R. leg } \\
\text { studied. + d.2 }\end{array}$ \\
\hline IMI & Severe HMD. IPPV \\
\hline Inc & Mild HMI). headhox () \\
\hline Inc & Well \\
\hline Inc & Well \\
\hline Inc & TIN, headbox 0 \\
\hline Inc & Well \\
\hline $\operatorname{Inc}$ & Well \\
\hline Inc & Mild HMI). headhox (): \\
\hline Inc & Well \\
\hline IMI & Severe HMD. IPPV \\
\hline IMI & Severe HMI). IPPV \\
\hline
\end{tabular}

' (iA. gestational age. completed wk: B.Wt. Birth weight: IMI. open incubator. using radiant heater: TTN. transient tachypnea of the newborn: IIAC. umbilical arterial catheter: Inc. (losed incuhator: BPI), hronchopulmonary dyoplasia: HMI), hyaline membrane disease: BA. hirth asphyvia: IPPV, receiving intermittent positive pressure ventilation: IVH, intraventricular hemorrhage.

An infant described as well is well at the time of study, but might have had carlier illness.

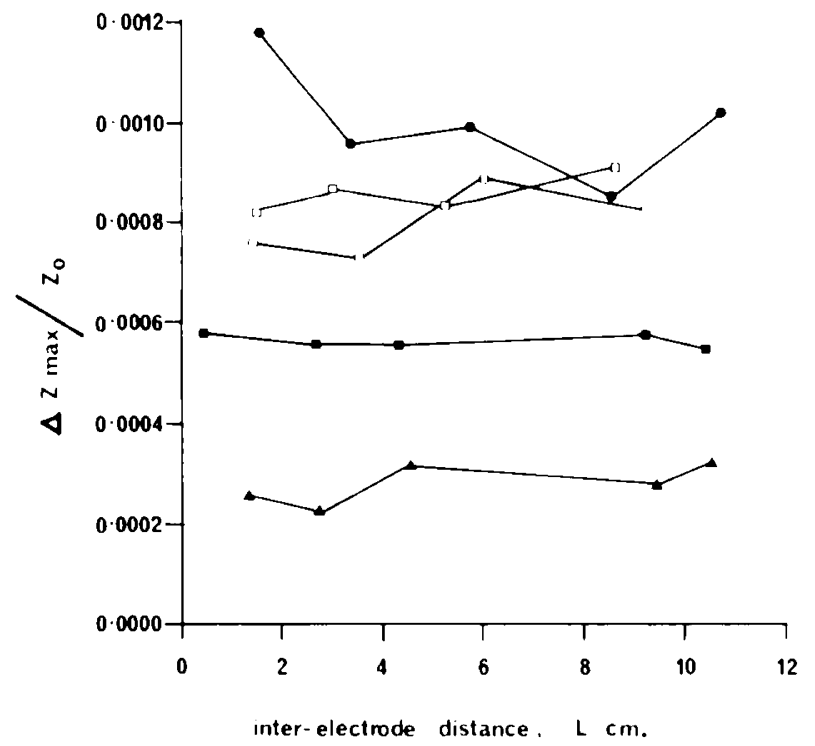

Fig. 4. The relationship between the ratio of maximum pulsatile impedance change to mean limb impedance and the interrecording electrode distance. $\mathrm{L} \mathrm{cm}$. (Fig. 1), studied in 5 separate babies. recordings were not made from subjects 1 to 4 because amplification of the signal was not adequate at that time. The failure of strain gauge occlusion measurements in subject 7 was due to electrical problems. and all other failures of strain gauge measurements were due to the difficulty of obtaining satisfactory records in dyspneic babies. Satisfactory pulsatile impedance recordings were obtained from all babies, although in the case of subject 22 the left leg was studied initially. and no pulse was obtained. This leg was dusky and clinically pulseless following the insertion of an umbilical arterial catheter which had been rapidly withdrawn. Good recordings were made from the right leg of this baby. At post-mortem examination following death from severe hyaline membrane disease on the second day of life. it was found that the left common iliac artery was completely occluded by antemortem thrombus. This was the only occasion on which no impedance recording could be made. (iond recordings were made from subjects 6 and 11 . despite the fatt that they had no pulses palpable below the femoral arteries.

The impedance and strain gauge pulses were lound to be strikingly different in form (see Fig. 2). The impedance pulse waveform has a more rapid rise than that obtained with the strain gauge. In most babies. especially the more dyspneic, a respiratoryrelated component of both impedance and strain gauge signals was present. but this was much more apparent in the strain gauge recordings. 
Table 2. Results of comparative strain gauge and electrical impedance measurements

\begin{tabular}{|c|c|c|c|c|c|c|c|c|c|c|}
\hline \multirow[b]{2}{*}{ Subject } & \multirow[b]{2}{*}{$\begin{array}{c}F\left(S\left(G_{\ldots, \ldots}\right)^{\prime}\right. \\
(\mathrm{ml} \mathrm{l}(\mathcal{N}) \\
\left.\mathrm{m} !^{\prime} \min { }^{\prime}\right)\end{array}$} & \multicolumn{5}{|c|}{ Strain gauge pulses } & \multicolumn{3}{|c|}{ Impedance pulses } & \multirow{2}{*}{$\begin{array}{l}- \\
F\left(Z_{\max }\right) \\
(\mathrm{ml} . \quad 100 \\
\mathrm{ml} / \mathrm{min})\end{array}$} \\
\hline & & $\begin{array}{c}\dot{H} \\
\text { (heats/min) }\end{array}$ & $\begin{array}{c}\mathrm{dSC}\left(\mathrm{j} / \mathrm{dt}_{\max }\right. \\
\mathrm{Rs}_{\mathrm{s}}{ }^{1}\end{array}$ & $\begin{array}{l}\mathrm{F}(\mathrm{S}(j \mathrm{I})) \\
(\mathrm{ml} . \mathrm{l}(00 \\
\mathrm{ml} / \mathrm{min})\end{array}$ & $\begin{array}{l}\mathrm{F}\left(\mathrm{SC} \mathrm{i}_{\max }\right. \\
(\mathrm{ml} \cdot \mathrm{l}(0) \\
\mathrm{ml} / \mathrm{min})\end{array}$ & $\begin{array}{c}Z_{t)} \\
\text { (ohm) }\end{array}$ & $\begin{array}{l}\mathrm{dZ} / \mathrm{dt}_{\max } \\
\text { (ohms ') }\end{array}$ & $\begin{array}{c}\mathrm{dZ} / \mathrm{dt}_{\max } \\
\left(Z_{\mathrm{s}^{*}} \quad{ }^{\prime}\right)\end{array}$ & $\begin{array}{l}\mathrm{F}(\mathrm{ZL}) \\
(\mathrm{ml} \cdot \mathrm{l}(00) \\
\mathrm{ml} / \mathrm{min})\end{array}$ & \\
\hline 1 & 13.4 & 128 & & & & 142 & 4.34 & 0.0306 & 10.9 & 10.8 \\
\hline 2 & 14.6 & 141 & & & & 139 & 4.66 & 0.0335 & 11.0 & 16.3 \\
\hline 3 & 11.1 & 126 & & & & 129 & 3.58 & 0.0277 & 13.7 & 14.8 \\
\hline 4 & 10.7 & 167 & & & & 132 & 2.69 & 0.0204 & 13.3 & 10.5 \\
\hline 5 & 5.9 & 116 & & & & 6.3 & 0.65 & 0.0103 & 9.0 & 5.7 \\
\hline 6 & 3.8 & 123 & & & & 78 & 1.10 & 0.0141 & 6.5 & 4.3 \\
\hline 7 & & 126 & $0.0(0) 34$ & 5.7 & 7.6 & 78 & 1.05 & 0.0135 & 4.6 & 8.0 \\
\hline 8 & 9.4 & 145 & $0.00,50$ & 12.6 & 7.0 & 1.37 & 3.43 & $0 .(1250$ & 15.8 & 14.3 \\
\hline$y$ & 19.2 & 164 & $0 .(0) \times 5$ & 23.3 & 11.5 & 106 & 2.53 & 0.0239 & 20.0 & 14.6 \\
\hline 10 & 6.3 & 129 & 0.00156 & 10.3 & 0.7 & 94 & 0.77 & 0.0082 & 3.4 & 5.1 \\
\hline 11 & & 153 & 0.01134 & 19.6 & 16.7 & 88 & 2.78 & 0.0316 & 11.9 & 17.3 \\
\hline 12 & 10.4 & 158 & 0.0074 & 12.4 & 7.1 & 84 & 2.99 & 0.0336 & 9.1 & 17.4 \\
\hline 13 & 19.7 & 140 & $0 .(1) 29$ & $x .1$ & 4.4 & 126 & 2.84 & 0.0225 & 13.5 & 14.7 \\
\hline 14 & 10.7 & 130 & & & & 125 & 1.67 & 0.0134 & 14.6 & 9.3 \\
\hline 15 & 10.0 & 143 & 0.00148 & 9.4 & 5.3 & 84 & 1.17 & 0.0139 & 8.5 & 8.6 \\
\hline 16 & 18.4 & 125 & & & & 6.3 & 1.54 & $0 .(1244$ & 6.2 & 14.1 \\
\hline 17 & 27.2 & 153 & 0.0107 & 22.8 & 13.5 & 94 & 3.08 & 0.0328 & 21.7 & 18.3 \\
\hline 18 & 7.5 & 129 & & & & 79 & 0.83 & 0.0105 & 3.5 & 6.2 \\
\hline 19 & 8.0 & 133 & $0.0(0) 99$ & 20.4 & 8.9 & 110 & 2.63 & 0.0239 & 8.9 & 9.9 \\
\hline 20 & 6.7 & 129 & $0 .(0) 73$ & 8.4 & 7.1 & 74 & 1.88 & 0.0254 & 4.5 & 9.5 \\
\hline 21 & 8.5 & 159 & $0.0(132$ & 7.8 & 4.0 & 115 & 2.58 & 0.0224 & 14.7 & 15.0 \\
\hline 22 & 7.6 & 154 & 0.60176 & 22.9 & 10.0 & 136 & 1.88 & 0.0138 & 10.9 & 9.7 \\
\hline 23 & 8.1 & 153 & $0.0(1) 41$ & 7.8 & 5.1 & 158 & 3.24 & 0.0205 & 14.9 & 16.6 \\
\hline 24 & $8 . x$ & 141 & (1). (1) 444 & 20.0 & 10.3 & 45 & 2.53 & 0.0266 & 12.9 & 11.4 \\
\hline 25 & 30.1 & 133 & $(1.013)$ & 23.9 & 15.7 & 104 & 3.82 & 0.0367 & 24.8 & 23.3 \\
\hline 26 & 19.5 & 127 & 0.0136 & 23.9 & 17.6 & 103 & 3.31 & 0.0321 & 5.0 & 12.4 \\
\hline 27 & 6.7 & 115 & (). $(0) 36$ & 6.1 & 3.5 & 70 & 0.73 & ().0104 & 3.0 & 5.9 \\
\hline 28 & 16.6 & 145 & $0 .(k) 2 x$ & 10.1 & 10.9 & 107 & 2.86 & 0.0267 & 12.1 & 15.5 \\
\hline 29 & & 123 & ().(k)44 & 10.8 & 4.7 & 112 & 3.54 & 0.0316 & 10.2 & 14.2 \\
\hline 30 & $4 . x$ & 120 & 0.00133 & 11.2 & 4.9 & 99 & 1.67 & 0.0169 & 9.5 & 7.8 \\
\hline 31 & 5.9 & 123 & 0.10121 & 3.9 & 2.5 & 117 & 1.15 & 0.00999 & 3.5 & 4.8 \\
\hline 32 & 14.1 & $1 \times 6$ & 0.0185 & 35.3 & 21.3 & 88 & 2.37 & 0.0269 & 12.3 & 15.1 \\
\hline 33 & 10.4 & 143 & $0 .(k) 64$ & 14.2 & 7.9 & 42 & 1.59 & 0.0379 & 10.0 & 7.4 \\
\hline
\end{tabular}


upslope of the pulse recorded using the strain gauge: $1 /(S(; 1))$ and $F\left(S\left(i_{m} \ldots\right)\right.$. blood flow calculated from the end of the pulse cycle and the maximum pulse height recorded using the strain gauge (see text): $Z_{1}$. mean baseline electrical impedance: $\mathrm{d} Z / \mathrm{dt}_{\text {max. }}$ maximum change of impedance seen during

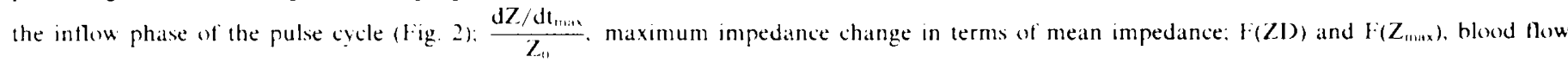
calculated from the end of the pulse cycle and the maximum impedance pulse height.

The reproducibility of the various estimates of flow is shown in Table 3. It can be seen that the beat-to-beat reproducibility of simultaneous measurements from the upslopes and from the maximum pulse heights was greater from the impedance recordings than from strain gatuge recordings. The reproducibility of the impedance estimations in subjects 5, 6. 14, 16, and 18 (Table 1) was less goend than in the other bathies because of the presence of respiratory related components: it is emphasized. however. that the strain gauge recordings from these babies were so much more distorted as to be rendered useless for analysis. The reproducibility of flow estimations from the slopes at the end of the pulse cycle $\left[1: Z_{1}\right)$ and $F(S(j D)]$ was poor for both methods.

The mean ( $V$ for 10 repeated measurements in six different subjects was greater for the strain gauge than for impedance measurements. Unfortunately. only one baby appears in both groups of six. In that subject. who was clinically well, the ( $\mathrm{V}$ of

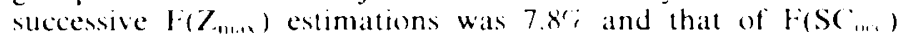
estimations was 17.9\%". Comparing the two groups of six babies. two of the impedance group and three in the strain gatuge group were receiving intermittant positive pressure ventilation. the re- maining three babies in the latter group being perfectly well, while two of the remaining four in the impedance group were severely tachypneic.

The results of linear regression analyses are shown in Table 4. It can be seen that each of the three estimates of flow from the pulsatile impedance signals correlates statistically significantly with the flow estimations made hy strain gatuge venous occlusion. The best correlation $(r=0.76)$ was between $\mathrm{F}\left(\mathrm{Z}_{\max }\right)$ and $\mathrm{F}\left(\mathrm{SC}_{1 \ldots}\right)$.

Because the aim of the comparisons was to assess how well estimations based on impedance pulse analysis might correlate with flow measurements made by strain gauge venous occlusion plethysmography. the latter was initially considered as the independent variable. $x$, in the regression analysis. For such analysis. the regression lines between $F\left(Z_{\text {max }}\right)$ and $F\left(S G_{i_{1}}\right)$ and between $F\left(Z_{1}\right)$ and $F\left(S C_{1 . .1}\right)$ were found to be statistically significantly different from the line of identity $(P<0 .(0) 1)$. However, because the reproducibility of the variable $F\left(Z_{\max }\right)$ was significantly better than that of $F\left(S G_{m}\right)$, it is valid to consider the impedance estimates of flow as the independent variables. When the analysis was performed in this way, the regression line between $\mathrm{F}\left(\mathrm{S}\left(\mathrm{j}_{\mathrm{i}} ..\right)\right.$ 


\section{Table 3. Reproducibility of observations}

Pulsatile data, 10 successive beats simultaneously recorded $(n=24)$

Strain galuge

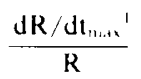

( $\mathrm{V}^{\prime}$

$\begin{array}{lc}\text { Mean } & 21.0 \\ \text { Range } & (6.3 .49 .8) \\ \text { No. of subjects } & 21\end{array}$

21

\section{$F(S(i D))$}

38.1

$(6.371 .2)$

22

$0.3,0.3$

$H\left(S\left(i_{m i n}\right)\right.$

17.4

$(5.945 .31$

18

Impedance

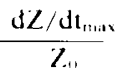

$F\left(Z_{1}\right)$

$F\left(Z_{\min }\right)$

9.1

$(4.3-16.9)$

36.8

(11.3.93.1)

7.8

8

24

\footnotetext{
10 impedance recordings at $3(1)$-sec intervals $(n=6)$

$1\left(Z_{m+1,}\right)$

( $\mathrm{V}^{\prime}$

Mean

Range

9.8

(6.) 13.5 )

Pulse volume

9.1

(3.) 14.0)

Z"

1.2

(10.0 1.9 )

iI

3.1

(0.5-4.5)

( V';

Mean

10 measurements of $f(S(j, \ldots)$ at 30 -sec intervals $(n=h)$

Range

16.1

$(5.7-27.6)$

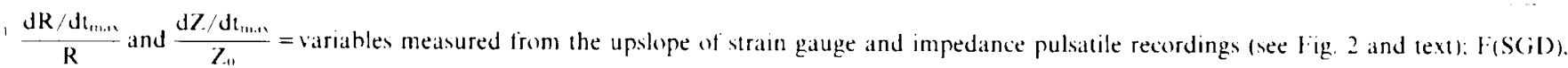

$F\left(S\left(i_{\max }\right), F(S(j D))\right.$ and $F\left(S\left(i_{\max }\right)\right.$ : blood flow calculations from the end of the pulse cycle and maximum pulse heights from strain gauge and impedance recordings (see Fig. 3 and (ext); ( V. coefficient of variation (see text): $F\left(S\left(i_{\ldots},\right)_{1}\right.$, blood flow calculated using the strain gauge during venous occlusion: $\dot{H}$, heart rate.
}

\section{Table 4}

Variables

\begin{tabular}{|c|c|c|c|c|c|c|c|}
\hline & $x$ & $y$ & $n$ & Regression equation & $r$ & $\begin{array}{l}\text { Statistical signifi- } \\
\text { cance of } r(P<)\end{array}$ & $\begin{array}{c}\text { compared with line of } \\
\text { identity }(P)\end{array}$ \\
\hline \multirow{8}{*}{$\begin{array}{l}\text { F(SC } . . ., \text { compared with } \\
\text { variables from pulsatile } \\
\text { traces }\end{array}$} & f 1 (SC $; \ldots)$ & $f(\gamma, \ldots, n)$ & 30 & $=-5.14+0.50 x$ & 0.76 & $0.0(1)$ & $=(0 .(x))$ \\
\hline & $\mid 1\left(Z_{2 \ldots \ldots}\right)$ & $f(S(i, \ldots)$ & 30 & $y=0.33+1.03 x$ & 0.76 & 0.001 & $>(1.9 \times 0$ \\
\hline & $\begin{array}{l}\mathrm{F}\left(\mathrm{S}\left(\boldsymbol{i}_{\ldots} . .\right)\right. \\
\mathrm{H}\left(\mathrm{S}\left(i_{\ldots}\right)\right.\end{array}$ & $(Z D)$ & 30 & $y=4.51+0.54 x$ & 0.64 & 0.001 & $>0.001$ \\
\hline & $\int \operatorname{los}\left(i_{\ldots}\right)$ & $\frac{\mathrm{d} Z: \mathrm{dt}_{1 \mathrm{nat}}}{Z_{\mathrm{a}}}$ & 30 & $y=0.0124+0.000(09 x$ & 0.6 .3 & 0.001 & \\
\hline & $\frac{\mathrm{d} Z: \mathrm{d} \mathrm{d}_{1 \ldots \ldots}}{Z_{\ldots 1}}$ & Fis(; $;.)$, & 30 & $y=1.2 x+467 x$ & 0.6 .3 & 0.001 & \\
\hline & $\operatorname{lis}\left(i_{1 . .}\right)$ & $\operatorname{lis}\left(i_{1 \ldots \ldots}\right)$ & 21 & $y=3.55+01.43 x$ & 0.62 & 0.01 & $<0 .(4) 1$ \\
\hline & F(S $\left(i_{1 . .}\right)$ & $\mid(S(i))$ & 21 & $y=7.47+0.57 x$ & 0.50 & 0.05 & N.S. \\
\hline & Fis $(; \ldots)$ & $\frac{d R: d t_{1 \ldots n}}{R}$ & 21 & $y=0 .(1) 40+0.040(3) .3 x$ & 0.43 & N.S. & \\
\hline \multirow{5}{*}{$\begin{array}{c}\text { Comparison of simulta- } \\
\text { neous pulsatile traces }\end{array}$} & $\int 1+S\left(i_{1 \ldots 1}\right)$ & $I\left(Z_{\ldots \ldots}\right)$ & 24 & $y=8.11+0.48 x$ & 0.50 & 0.01 & $<0.01$ \\
\hline & $\mid 1\left(Z_{+\ldots+1}\right)$ & $I\left(S\left(i_{1 \ldots . .1}\right)\right.$ & 24 & $y=2.50+0.52 x$ & 0.50 & 0.01 & $<0.025$ \\
\hline & $f(S(i))$ & $l\left(Z_{1,1}\right)$ & 24 & $y=6.11+0.34 x$ & 0.46 & 0.05 & $<0 .(k) 1$ \\
\hline & $\int \frac{\mathrm{dR}: \mathrm{d} \mathrm{t}_{\mathrm{n} \ldots \mathrm{N}}}{\mathrm{R}}$ & $\frac{\mathrm{d} Z: \mathrm{dt} \mathrm{t}_{\ldots . .1}}{Z_{1}}$ & 24 & $y=2.50+414 x$ & 0.77 & 0.001 & \\
\hline & $\int \frac{\mathrm{d} Z: \mathrm{dt} t_{1 \ldots . .}}{Z}$ & $\frac{d R: d t_{1 \ldots . .1}}{R}$ & 24 & $y=1) .(10)(1997+0.270 x$ & 0.77 & $(0 .(6) 1$ & \\
\hline
\end{tabular}

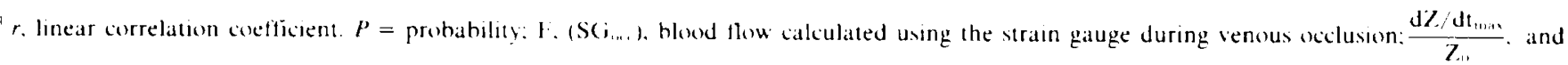

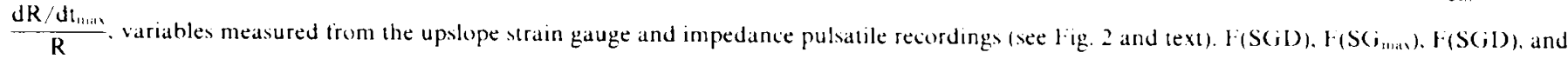
$\mathrm{F}\left(\mathrm{S}\left(\mathrm{i}_{\text {m.n. }}\right)\right.$. blood flow calculations from the end of the pulse cycle and maximum pulse heights from strain gauge and impedance recordings (see $\mathrm{Fig}$. 3 and text). 
and $F\left(Z_{\operatorname{man}}\right)$ was not statistically significantly different from the line of identity $(P<0.98)$, and the intercept of the line is very close to zero (Fig. 5 ).

The correlation coefficient between $\mathrm{F}\left(\mathrm{S}\left(\xi_{1, \ldots}\right)\right.$ and the variables $\mathrm{F}\left(\mathrm{SG}_{\max }\right)$ and $\mathrm{F}\left(\mathrm{SG}_{1}\right)$ reached statistical significance $(P<$ 0.01 and $<0.05$. respectively), but these coeflicients were lower than those obtained with the variables from the impedance pulse. Furthermore, the regression lines differed statistically significantly from the line of identity. The relationship between the value $\frac{\left(\mathrm{dR} / \mathrm{dt}_{\text {nax }}\right)}{\mathrm{R}}$. and $\mathrm{F}\left(\mathrm{S}\left(\mathrm{j}_{\ldots, \ldots}\right)\right.$ did not reach statistical significance.

The linear correlations between the simultaneously recorded impedance and strain gauge pulses reached statistical significance. but, with the exception of the upslope correlation. i.e., $\frac{\left(\mathrm{dR} / \mathrm{dt}_{\text {max }}\right)}{\mathrm{R}}$. with $\frac{\left(\mathrm{dZ} / \mathrm{dt}_{\max }\right)}{Z_{11}}$; the coefticients were comparatively low, and the regression lines differed significantly from the lines of identity.

\section{I)ISC USSION}

The results show that of the methods of analysis performed the estimation of limb blood flow using the maximum pulsatile impedance change. $\mathrm{F}\left(Z_{\max }\right)$, gave the best correlation with strain gauge venous occlusion estimations. $F\left(S\left(j_{\ldots},\right)\right)$ and that it was the most reproducible beat-to-beat estimation. This is in accordance with experience in adults, and animals where the maximum height of the impedance pulse, $\Delta Z_{\text {sain, }}$ has been used for the estimation of blood flow. where it has been found to correlate well with simultaneous measurements using electromagnetic llowmeters (20).

Estimation of tlow based on the downslope of the impedance pulse at the end of the pulse cycle is based upon the assumption that venous flow is nonpulsatile and that there is no forward flow in the artery at the end of the pulse cycle (4). We have confirmed that venous flow is indeed nonpulsatile in the newborn infant with the use of a Doppler ultrasound probe positioned over the femoral vein. In addition. it has been found that while there is generally no forward flow in the femoral or popliteal arteries at the end of the pulse eycle there may in fact be reverse llow which could invalidate the calculation. Neither is it possible to saly that these

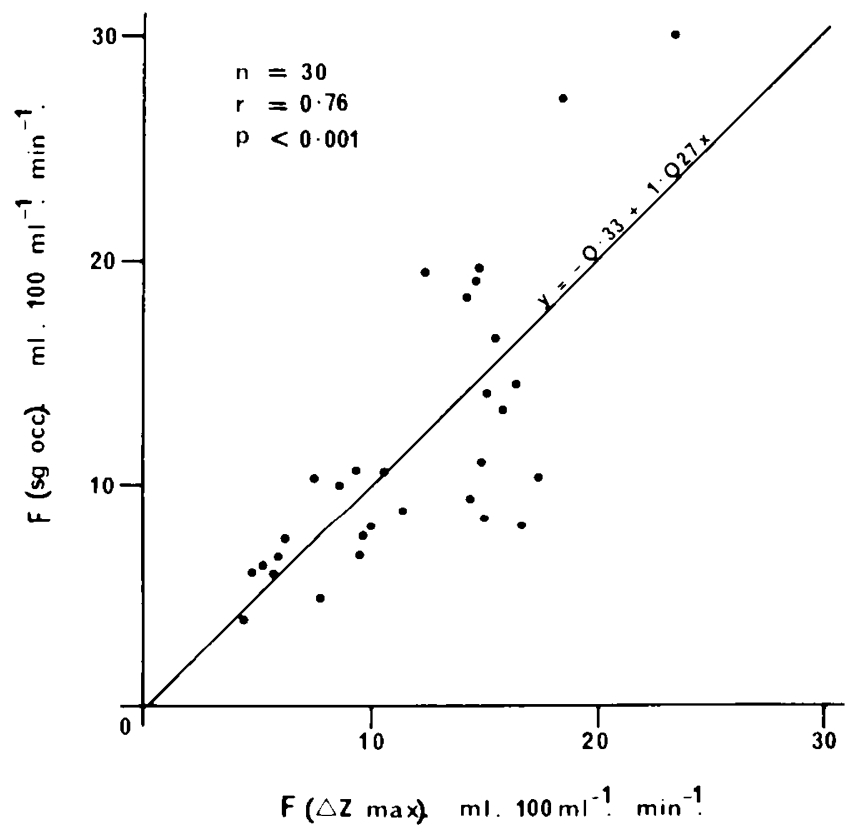

Fig. S Relationship hetween blood flow measured using the strain

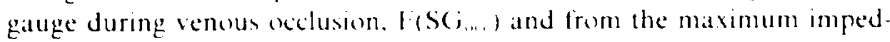
ance pulse height. $F\left(Z_{\text {m... }}\right)$. The regression line as statistically signiticantly similar to the line of identity $P>0.98$ findings in the great vessels may be extrapolated to predict what might occur in the smaller vessels. The basis for this form of estimation therefore appears to be unreliable. although it does represent an attempt to overcome the difficulties of correcting for venous and arterial runoff which is necessary for the accurate analysis of pulsatile recordings

The third method of pulse analysis. based on a measurement of the maximum rate of change of impedance at the beginning of the pulse cycle, $\mathrm{dZ} / \mathrm{dt}_{\text {max. }}$. Was considered in this study because of the success of a similar analysis in estimating stroke volume (11). dZ/ $\mathrm{dt}_{\text {max }} w_{\text {as }}$ expressed as a fraction of $Z_{11}$ so that it should be directly comparable with the corresponding slope of the strain gauge pulse. $\left(\mathrm{dR} / \mathrm{dt}_{\text {max }} / \mathrm{R}\right)$. It was also necessary to express the results in this way to arrive at the correct dimensions for the flow estimation.

Other methods of pulse analysis have been described using extrapolation of the slopes (2) and integration of the pulse form (15, 16). The basis for these forms of analysis appears not to have been justified theoretically. and when results obtained in the present study were analyzed using these methods. no improvement in beat-to-beat reproducibility or correlation between pulsatile and venous occlusion flow estimations was gained.

Some of the values calculated for limb flow in this study using both the impedance and strain gauge techniques are higher than previously reported values from the newborn except in experimentally induced reactive hyperaemia $(5,18)$ or in a very $x$ arm environment (9). This is likely to be due to the variety of circumstances under which babies were studied some of which would lead to increased peripheral blood llow. such as the presence of patent ductus arteriosus. the use of phototherapy. and nursing under radiant heaters.

Although the results of this study indicate that at least one technique of impedance pulse analysis can provide limb blood llow estimations which correlate with the established method of strain gauge venous occlusion plethysmography. they also lead one to raise objections to the use of the strain gauge method as a standard. However. for measurements in the newborn. no better alternative standard technique exists. The major problems encountered in this study with the strain gatuge method were concerned both with the practical application of the gauge and with the repreducibility of the measurements made. Although the very fine silicone rubber tubing used for the gauges was found to be robust. there was a constant need (o) reposition the gauge on the leg because there was a tendency for it to roll up or down the calt as the haby moved. This would make long-lerm use of the method satisfactory. Movement-induced artefact was found to be a problem with the strain gauge method both when making pulsatile recordings and during attempts to make venous occlusion estimations. Iespite the fact that satisfactory tracings were eventually obtained with the strain gauge from 30 of the 33 babies success was often not achieved at the first attempt because of movement related artefacts occurring both before and during the occlusion which made reliable measurement of the occlusion slope difficult and sometimes impossible. For this reason. pulse and venous occlusion estimations in the same baby were often separated in time by as much as 10 min. Previous reports of studies using the mercury-in-rubber strain gauge method in the newborn have not emplasised this problem which was possibly accentlatled in this work because of the heterogeneous nature of the group of babies studied, several of whom were very ill at the time of study.

In constrast to the problems associated with the strain gatuge method. the electrical impedance recordings were comparatively easy to obtain: in only one infant. in whom the common iliac artery was shown to be completely oceluded. Was it impossible to analye the electrical impedance pulses. The atutomatic balancing device of the impedance instrument wats used during all recordings. but the signal was so stable that it was not needed during the comparatively short periods of time when recordings were being made. However, the auto-balance facility was useful for eliminating large variations in the baseline which occurred between recordings when collecting intermittent data as was the case when 
estimating the reproducibility of the technique. Furthermore. the auto-balance feature would be essential for long-term data collection.

The calculations of reproducibility of the various estimations (Table 3) must include physiological beat-to-beat variation. In particular, respiration can be expected to produce beat-to-beat variation of pulse volume, probably of the order of $\pm 10 \%$. This level of reproducibility was only achieved for $\left.\mathrm{dZ} / \mathrm{dt}_{\max }\right) \cdot / \mathrm{Z}_{11}$ and $F\left(Z_{\operatorname{tax}}\right)$. The particularly poor reproducibility of $F\left(S G_{1}\right)$ and $F\left(Z_{1}\right)$ is because these estimations are derived from the slope of a comparatively low-frequency portion of the pulsatile signal which is more susceptible to hase line variations. For this reason, it is considered that the estimation of flow from the end of the downslope is not suitable as a method for long-term beat-to-beat flow assessment. The poorer reproducibility of the strain gauge estimations compared with impedance estimations fully justifies considering the electrical impedance estimations as the independent variable in the regression analysis.

There are fundamental reasons why one might expect to obtain different results with the electrical impedance and strain gauge techniques. The latter responds solely to mechanical phenomena. whereas the impedance method will be influenced by both mechanical and electrical phenomena. The difference in the form of the pulses obtained with the two techniques has already been mentioned. The rapid upslope of the impedance pulse is probably due to the fact that as soon as blood enters the large arteries in the limb segment an electrical impedance change will be seen, but its arrival will not be detected immediately by the strain gauge until the blood has been distributed through the tissues and produced a change in limb circumference. Furthermore. a change in the electrical impedance of the limb can be observed simply due to a change in the alignment of red blood cells (17) and in the redistribution of a fixed volume of blood from large arteries to capillaries. Although both methods should be capable of providing the same information, this will only be achieved if the methods of analysis take account of these fundamental differences.

The equation used as the basis for the impedance calculations (equation 2 ) has been used by various authors $(8,10,13)$, but its derivation deserves comment. The electrical resistivity of blood is eliminated from the equation by making the substitution $\rho=$ Z...A/I. However, the relationship used to make this substitution is in fact an expression for the mean resistivity of the tissue segment. $\rho_{1}$. Thus, the derivation of the equation assumes that blood resistivity, $\rho_{\mathrm{b}}$, is the same as $\rho_{\mathrm{t}}$. Blood resistivity varies with temperature. blood motion, and haematocrit. Measurements made at $37^{\circ} \mathrm{C}$ on fresh samples of whole blood from newborn infants have shown an exponential relationship between $\rho_{1}$, and haematocrit: $\rho=67.919 \exp (0.02433 \mathrm{Hct})(13)$.

At a haematocrit of 40$)^{\prime \prime}$. the resistivity is $180 \mathrm{ohm} \mathrm{cm}$ and at $55 \%$ is $259 \mathrm{ohm} \mathrm{cm}$. Kubicek 't al. (10) have measured $\rho_{1}$ in 8 adult subjects and found a mean value of $211 \mathrm{ohm} \mathrm{cm} .12$ of the babies in the present study had careful measurements made of the mean interelectrode distance $(\mathrm{L} \mathrm{cm})$ and the mean calf circumference, $\mathrm{C} \mathrm{cm}$, and $\rho_{1}$, calculated from the relationship $\rho_{1}=\mathrm{C}^{-2} Z_{11} / 4$, was found to have a mean value of $200 \mathrm{ohm} \mathrm{cm}$ (range. 173 to 246). Thus. some error must be introduced by the assumption that $\rho_{1}=\rho_{1}$. However. it is felt that this error is no larger than that which would be introduced by attempting to make measurements of haematoocrit, interelectrode distance. and leg circumference because the latter two measurements are associated with a significant error in the small leg of a preterm infant.

The measurement of $\Delta Z_{\text {max }}$ and the subsequent calculation of $\mathrm{F}\left(\mathrm{Z}_{\max }\right)$ could be automated and thus provide continuous beat-to- beat blood flow estimations. Although the accuracy of these estimations in absolute terms is likely to be only moderate. the reproducibility is good. and the technique simple and sale to apply. We feel that at present there is no better technique for making noninvasive estimations of peripheral blood flow in the newborn, and we believe that this method could provide valuable information from acutely ill babies.

\section{RIFERINCES ANI) N(OTIS}

1. Allson. R. 1). The elfects of agng. sascular desease and hrpertensen on the

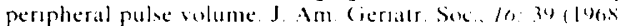

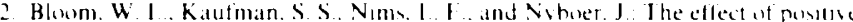

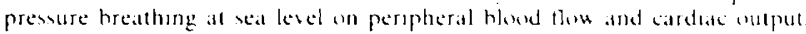
Natl. Res counc (iomm. Niation Med. Report $246(19+4)$

3. Bonjer. F. 11. : Circulatieonderach dour Impedantiemeung (ironingen. D)ruh kerij I. Oppenherm. N. V., |y5(1)

4. Brown. B. H. Pryce. W. I. J.. Baumber. 1). and (Jarke. R. (;. Impedatlic plethymography: can it measure changes in limb hlond tho Ned Bal Ing. 12: $074(1975)$

5. (elander. ().. Bloud llow in the fiont and calf of the new horn. A plethromographe

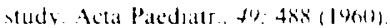

6. (inuch. N D). Van de Waler. J. M. and Dmochourhs. M. D). Nonnmasue

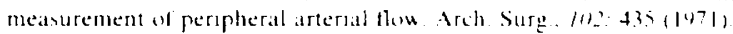

7. Hallbosk. T.. Masson. B., and Nolsen. R. A stran gatuge plethwmograph wath electrical calibration Scand J (lin I ah Invere $25+13(1971)$.

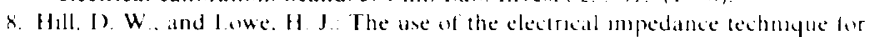

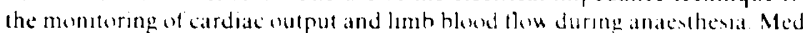
Biol . Ing. 11:534 (1973)

9. Kidd. 1... Ievenn. H. (iemmel. P. Aharon. A and Suser. P. R. I mh hlund

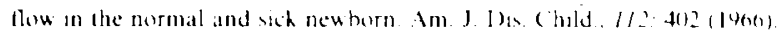

10. Kubicek. W. (j.. Witsoce, D) A.. Patterson. R. P.. and From. A H. I. Development and evaluation of an impedance cardiographic sistem to measure cardia output and other cardiac parameters. Final Progress Report. Contract NAS y $45(x)$. NASA Manned Space (raft (entre. Hounton. Texas (1970).

11. Mohapatra. S. N. Nonmbasive cardac momtosmg by electrcal ampedance plethymography. Ph.D). Thess, london ('nuersll, (i)77),

12. Mohapatra. S. N and trensen. H $M$. The measurement of peropheral blend llow by the electrical impedance lechnyue. J . Med 1.ng. Tech. 3: 132 (1979)

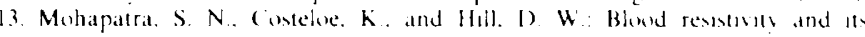
implications for the calculatem of cardac output bo the theracte electracal

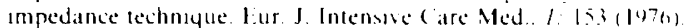

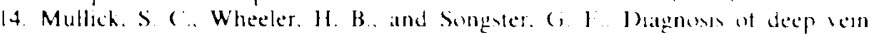
thromboss by measurement of electrical mpedance. Am J. Surg.. / $11 \%$ ? (1070).

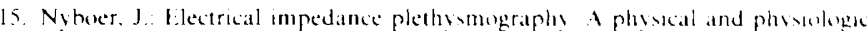



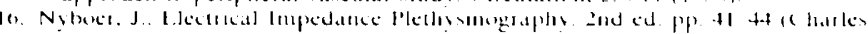
(C Thomas. Spronglietd. 11.. 19711,

17. Peura, R. A. Whecter. W H. Pennes, B ( . and Arcuns, J Impedante plethromography: relatue contribution of blend whlume and red cell velocits changes on the sienal strength Degest of the 11 th lnternational (interence of

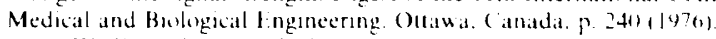

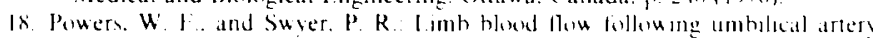

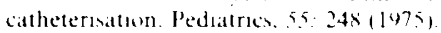

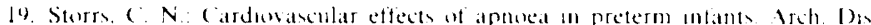
( hild. 52:534(1977)

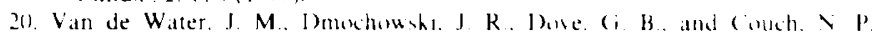

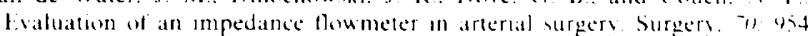
(1971).

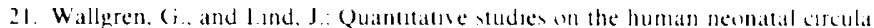

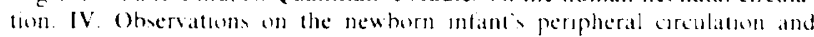

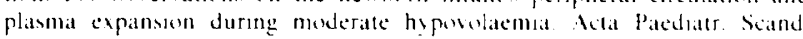
Suppl.. $\left.I^{-1)} 5511967\right)$.

32 Whanes. R. J The measurement of solume changes in human lambs J Phwol. $1: 1: 1(1953)$

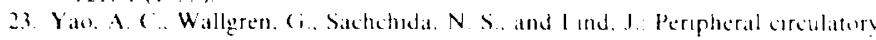
response of feeding in the newhorn onfant. Pedatros, f 375 (1971)

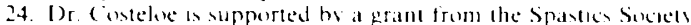

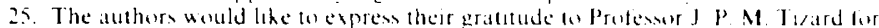
help with the preparateon of the manuscript

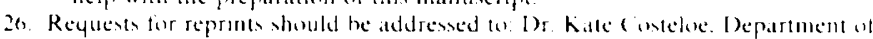

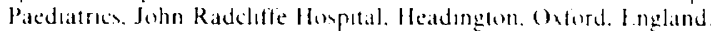

27. Receised for publicalion september 26. 1979

2x. Accepled for publicatoon December 13. 1974 